\title{
CARDANO E OS JOGOS DE AZAR*
}

\author{
Júlio Faria Corrêa / Felipe Faust Bernal
}

\begin{abstract}
Resumo:
O objetivo deste capítulo é problematizar o desenvolvimento da Teoria das Probabilidades na obra "Liber De Ludo Aleae" de Girolamo Cardano (1501-1576), publicada postumamente em 1663, em conexão com o campo dos jogos de azar. O capítulo está dividido em quatro seções. Na primeira problematizamos os jogos de azar do ponto de vista conceitual e histórico. Na segunda seção apresentamos uma breve biografia de Cardano. Na terceira apresentamos o "Liber de Ludo Aleae", bem como os conceitos de probabilidade ali encontrados. Por fim, problematizamos a relação da forma como esses conceitos surgiram pela obra de Cardano com o que é apresentado em livros didáticos da Educação Básica sobre probabilidades. Destacando que, apesar de utilizarem diversas situações que remetem indiretamente aos jogos de azar, os livros analisados acabam por criar situações que desconsideram as formas de vida em que as práticas dos jogos de azar são realizadas. Assim, a história permite realizar uma conexão do conteúdo que aparece nos livros com a riqueza das formas de vida em que emergiram.
\end{abstract}

Palavras-chave: História da Matemática. Probabilidades. Cardano. Jogos de Azar. BNCC.

Naturalmente, para um matemático, um erro traz apenas um certo embaraço, mas para um apostador é uma questão vital. Assim, é compreensível que, quando estamos falando da primeira teoria sistemática da probabilidade, o primeiro a desvendar a coisa tenha sido Cardano, o apostador. (MLODINOW, 2009, p. 77)

\section{Introdução}

O presente capítulo é resultado de um trabalho de Iniciação Científica realizado na Universidade Federal de Santa Catarina, Campus Blumenau, cujo objetivo foi o estudo dos desenvolvimentos de Girolamo Cardano no campo das probabilidades de maneira a relacioná-lo com a busca pelo controle da incerteza nos jogos de azar. Esse pensador italiano do século XVI é mais conhecido na História da Matemática pela querela com Tartaglia sobre a solução de equações de terceiro grau, mas este capítulo se dedica à investigação de uma obra menos conhecida, o "Liber de Ludo Aleae" (O Livro dos Jogos de Azar), no qual Cardano realiza um estudo dos jogos de azar e desenvolve algumas das ideias que hoje pertencem a teoria das probabilidades.

O interesse pelo estudo da história das probabilidades está relacionada a dois fatores que se correlacionam. A Teoria das Probabilidades, apesar de ser relativamente recente, é reconhecida como um importante ramo da Matemática. Ela possui diversas

\footnotetext{
* DOI - 10.29388/978-65-86678-51-2-0-f.155-174
} 
aplicações em áreas de estudo além da Matemática, como finanças, estatística, física, inteligência artificial, teoria dos jogos e até mesmo filosofia. Assim, o primeiro fator está relacionado com o aumento da presença do estudo das probabilidades proposto pela Base Nacional Comum Curricular (BNCC) em relação aos Parâmetros Curriculares Nacionais (PCNs), que pode ser indicado não apenas pelo surgimento da unidade temática Probabilidade e Estatística - que entrou no lugar do Tratamento da Informação dos PCNs -, mas também pelo fato dessa unidade temática ter se ampliado para os Anos Iniciais do Ensino Fundamental. Diz a BNCC: "A incerteza e o tratamento de dados são estudados na unidade temática Probabilidade e estatística" (BRASIL, 2017, p. 274).

Analisando mais detidamente o documento em questão, a BNCC divide o ensino das probabilidades no Ensino Fundamental em dois momentos: Anos Iniciais e Anos Finais. Nos Anos Iniciais, que vão do primeiro ao quinto ano, o enfoque está em mostrar aos alunos que nem todos os eventos são determinísticos. A compreensão do conceito de aleatoriedade é essencial, levando os estudantes a entenderem que eventos podem ser certos, possíveis ou impossíveis. Já nos Anos Finais, do sexto ao nono ano, os alunos devem começar a realizar experimentos aleatórios e compará-los com os resultados esperados pelos cálculos de probabilidade.

Espera-se, portanto, que as crianças sejam capazes de compreender o acaso e que os adolescentes consigam matematizá-lo. Hoje isso pode parecer uma exigência razoável, visto que os sistemas de ensino de vários outros países também trabalham com esses temas desde os anos iniciais. No entanto, o acaso foi um enigma por muito tempo, e apenas em torno dos séculos XVI e XVII é que os matemáticos realmente começaram a entendê-lo e a construir teorias da probabilidade.

Esse aumento da presença da probabilidade (e da estatística) na proposta curricular brasileira está relacionado ao segundo fator que levou ao interesse no estudo da história das probabilidade, que poderíamos indicar como sendo a emergência do sujeito neoliberal. No livro "A nova razão do mundo", Pierre Dardot e Christian Laval (2016) procuram caracterizar o atual momento histórico do capitalismo, o neoliberalismo, por meio da nova racionalidade neoliberal que fundamenta a liberdade individual no princípio da competitividade, da concorrência sem limites, que cria um sujeito que assume para si a lógica da empresa, sua racionalidade. Ao assumir para si essa racionalidade, o sujeito neoliberal transforma-se num sujeito concorrencial que deve competir constantemente para a sobrevivência, além de assumir os riscos envolvidos nessa empreitada.

Com a desconstrução do estado de seguridade social operada pelo neoliberalismo, cabe cada vez mais ao indivíduo a gestão dos riscos relativos ao empreendimento de si mesmo. Riscos educacionais, riscos de saúde, riscos de transporte, etc. Assim, o cálculo do risco passa a ser fundamental nas sociedades contemporâneas. O empresário de si mesmo precisa prever os riscos, matematizar a incerteza para minimizar perdas. É nesse contexto que a presença cada vez maior da Probabilidade e da Estatística na Educação Básica pode ser compreendida.

Esses dois fatores mobilizaram o desenvolvimento do estudo da história das probabilidades. A escolha de Cardano deu-se, em parte, por um embate sobre se teria sido ele o primeiro a desenvolver a fórmula para o cálculo de probabilidades. No livro "O andar do Bêbado: como o acaso determina nossas vidas" - de onde foi retirada a epígrafe deste capítulo - Leonard Mlodinow parece argumentar por uma originalidade de Cardano quanto 
a sistematização das probabilidades. Para essa argumentação, Mlodinow (2009) utiliza o livro “Cardano: The Gambling Scholar” de Oystein Ore (1953), que também nos serve de base e que segue a mesma linha de argumentação, procurando mostrar que no "Liber de Ludo Aleae" teríamos os primeiros elementos de uma teoria de probabilidades.

Nesse mesmo sentido, Ian Hacking (2009), no livro "The emergence of probability: A philosophical study of early ideas about probability, induction and statistical inference", afirma ter sido Cardano o autor do primeiro livro sobre probabilidades. Entretanto, Hacking nos lembra que esse livro, produzido por volta de 1550, foi publicado apenas em 1663 e não teve uma grande repercussão e que, além disso, uma organização sistemática das probabilidades emergiu por volta de 1660, não a partir do trabalho de Cardano, mas a partir de trabalhos de Pascal e outros estudiosos da época.

Será defendido neste capítulo que os jogos de azar tiveram um importante papel no surgimento de conceitos que hoje pertencem à teoria das probabilidades, e que no livro de Cardano, apesar de não existir tal teoria, podemos encontrar semelhanças de família com alguns dos conceitos da probabilidade.

Este capítulo está dividido em quatro seções. Na primeira problematizamos os jogos de azar do ponto de vista conceitual e histórico. Na segunda seção apresentamos uma breve biografia de Cardano. Na terceira apresentamos o "Liber de Ludo Aleae", bem como os conceitos de probabilidade ali encontrados. Por fim, problematizamos a relação da forma como esses conceitos surgiram pela obra de Cardano com o que é apresentado em livros didáticos da Educação Básica sobre probabilidades.

\section{Jogos de azar e Aleatoriedade}

O controle do acaso está ligado à necessidade humana de lidar com o imprevisível, o casual, aquilo que não se encaixa em leis determinísticas. O estudo das probabilidades emerge da tentativa de matematização do imprevisível. Dois grandes campos de atividade humana tiveram relação com essa emergência: o campo das práticas de asseguramento e o campo das práticas lúdicas. Entretanto, esse livro, que aborda o acaso de diferentes maneiras e a partir de diferentes campos de atividade humana, mostra que as práticas de asseguramento e as práticas lúdicas não são as únicas práticas a lidarem com o acaso, nem a se conectarem com a emergência da matematização das probabilidades. Apesar disso, nesse capítulo o foco será a relação do controle do acaso com as práticas lúdicas.

Os jogos, longe de serem meras distrações, são práticas humanas presentes em diferentes formas de vida que podem ser rastreadas ao longo da história. Essas práticas foram alvo, inclusive, de estudos acadêmicos que buscaram compreender a importância dos jogos na vida humana. Um famoso estudo sobre os jogos foi realizado pelo linguista e historiador holandês Johan Huizinga. Em seu livro "Homo Ludens", Huizinga (2012) propõe que tão importante quanto a razão (bomo sapiens) e a fabricação de objetos (bomo faber) é a compreensão do caráter lúdico das práticas humanas. Para realizar sua investigação, ele propõe uma caracterização do jogos:

Numa tentativa de resumir as características formais do jogo, poderíamos considerá-lo uma atividade livre, conscientemente tomada como "não-séria" e exterior à vida habitual, mas ao mesmo tempo capaz de absorver o jogador de 
maneira intensa e total. É uma atividade desligada de todo e qualquer interesse material, com a qual não se pode obter qualquer lucro, praticada dentro de limites espaciais e temporais próprios, segundo uma certa ordem e certas regras. Promove a formação de grupos sociais com tendência a rodearem-se de segredo e a sublinharem sua diferença em relação ao resto do mundo por meio de disfarces ou outros meios semelhantes (HUIZINGA, 2012, p. 116).

Essa caracterização é rapidamente confrontada com a questão dos jogos de azar, que são jogos nos quais a questão do lucro é fundamental. Tão fundamental quanto problemática, pois a prática de jogos de azar é, até os dias atuais, considerada perigosa a ponto de restringirem os locais em que se pode praticar os jogos de azar, ou mesmo criarem cidades isoladas, como a famosa Las Vegas, onde a prática é legal. Além da questão moral envolvida nos jogos de azar, o Estado tende a realizar um grande controle sobre eles por serem extremamente lucrativos.

Outro pensador contemporâneo, o sociólogo de origem francesa, Roger Caillois, desenvolve uma crítica da definição de jogo dado por Huizinga, destacando, entre outros pontos, a exclusão dos jogos de azar na delimitação realizada pelo linguista holandês. No livro "Os Jogos e os Homens", Caillois (1990) dedica uma seção aos jogos de azar, além de problematizar o papel do acaso nos jogos. O autor destaca que mesmo em uma civilização em que o trabalho tem um valor muito elevado, os jogos de azar possuem seu lugar. Isso é devido ao fato de, ao contrário dos baixos ganhos obtidos por um árduo e demorado trabalho, os jogos de azar permitem a geração de uma riqueza quase instantânea: “[...] o jogo escarnece do trabalho e representa uma solicitação rival, que pelo menos em alguns casos, assume importância bastante para determinar em parte o estilo de vida de toda uma sociedade" (CAILLOIS, 1990, p. 169).

Essa importância dos jogos de azar em certas formas de vida, de acordo com Caillois, tem a ver com a relação entre acaso e competição. Principalmente em nossas sociedades capitalistas contemporâneas, as práticas de competição são base do sistema meritocrático de recompensas: quem faz mais ou melhor, a princípio, tem uma recompensa maior. Em contrapartida, o acaso é tido como algo a ser repelido e que não deve ser fruto de recompensas, exceto em jogos de azar, como, por exemplo, as loterias. Excetuando-se os jogos legalizados, os jogos de azar podem servir como uma compensação para a meritocracia excludente que governa as sociedades atuais.

$\mathrm{Na}$ época de Cardano, muitos dos jogos que hoje servem de entretenimento, nos quais não são realizadas apostas, tais como xadrez, eram jogados valendo dinheiro. $O$ fato de conseguir um dinheiro "fácil" e "rápido", que complementasse a renda escassa que obtinha como médico, parece ter mobilizado Cardano, não apenas a praticar os jogos de azar compulsivamente, mas também a sistematizá-los de maneira a desenvolver os primeiros cálculos de probabilidade que conhecemos. Apesar do dinheiro fácil, nos primeiros capítulos do "Liber de Ludo Aleae" ele orienta os leitores a terem cautela em relação aos jogos de azar, não apenas pela possibilidade de perda de dinheiro, mas pela má reputação atribuída a eles. Ele chega a defender que os jogos devem ser praticados apenas pelo prazer e que, no caso de ocorrerem apostas “[...] deve haver moderação na quantidade 
de dinheiro envolvido, caso contrário, é certo que ninguém deve jamais jogar" (CARDANO, 1953, p. 186) ${ }^{1}$.

Nos primeiros capítulos de seu livro, Cardano apresenta uma série de conselhos aos jogadores. Além desse cuidado com a quantidade de dinheiro envolvida - que o próprio Cardano não parece ter respeitado ao jogar com nobres de sua época -, ele ressalta que o jogo de azar pode "[...] gerar raiva e distúrbios psíquicos, e que às vezes uma briga explode por conta do dinheiro, algo que é vergonhoso, perigoso e proibido por lei" (CARDANO, 1953, p. 186). Pessoas de renomada sabedoria também não devem se envolver em apostas, mas, em contrapartida, é menos repreensível que jovens e soldados se dediquem a tal prática. Cardano desaconselha que seus leitores joguem com apostadores profissionais e ressalta que o melhor e mais respeitável lugar para se jogar é em sua própria casa, ou na de amigos, para evitar escândalos.

Dentre as vantagens de praticar jogos de azar em um local respeitável estão o relaxamento e a possibilidade de conhecer quem realmente é seu oponente, pois "[...] raiva, ganância, e honestidade ou desonestidade são reveladas" (CARDANO, 1953, p. 188). Quanto às perdas, além do dinheiro, há perda de tempo, de palavras vãs, e mesmo a perda de reputação. Ao final desses capítulos introdutórios, Cardano procura justificar o que fez com que ele procurasse sistematizar os jogos de azar e apostas. Como médico, ele compara o vício a uma doença, pois da mesma maneira que um médico deve tratar um doente, alguém precisa explicar aos jogadores como lidar com as apostas para reduzir os prejuízos resultantes.

No livro "Cardano: The gambling scholar", Oystein Ore, além de apresentar uma versão adaptada do "Liber de Ludo Aleae", faz um apanhado histórico da vida de Cardano e de seu interesse pelos jogos. Segundo Ore, os quatro grandes jogos de azar na época de Cardano eram o xadrez ${ }^{2}$, o gamão ${ }^{3}$, os jogos de cartas e os jogos de dados. Cardano, um excelente enxadrista, relata que no verão de 1542 quase abandonou sua prática médica pelos lucros que obtinha jogando xadrez com um nobre. Após inúmeras derrotas, o nobre fez com que Cardano jurasse que não mais entraria em sua casa com o propósito de jogar xadrez.

Enquanto o jogo de xadrez tem como base as habilidades do jogador e os jogos de dados contam mais com a sorte, jogos como o gamão contam com esses dois elementos. $\mathrm{O}$ último tipo de jogo que interessou Cardano foram os jogos de cartas, que haviam surgido há apenas um século, sendo seu jogo favorito chamado Primero. Apesar de novos, os jogos de cartas eram inúmeros e muitos sobreviveram até hoje. Embora Cardano tenha se interessado por diferentes jogos, foi a partir dos dados que ele desenvolveu os conceitos de probabilidades que são o foco deste estudo.

Desde a Idade Média, os jogos de dados eram os mais frequentemente usados para apostas. Foi esse tipo de jogo que Cardano utilizou em seu livro para apresentar os cálculos de probabilidades. $\mathrm{Na}$ época de Cardano, o jogo mais comum era chamado de Hazard, nome que tem sua origem na expressão árabe al azar, que significa dado. Hazard é um jogo

\footnotetext{
1 Todas as traduções de Cardano (1930 e 1953) e Ore (1953) são nossas.

2 Pode nos parecer estranho considerar o xadrez um jogo de azar, mas Ore (1953, p. 109) clarifica que na época era costumeiro jogá-lo por dinheiro de maneira rápida e furiosa.

${ }^{3}$ Utilizamos aqui a palavra gamão para nos referirmos a uma família de jogos que existiam à época e que eram variações do que hoje conhecemos como gamão.
} 
com dois dados e com dois ou mais jogadores em que são estabelecidas uma série de regras que indicam, a partir do lance dos dois dados, quem ganha e quem perde. De acordo com a estatística Florence Nightingale David (1962), o jogo Hazard surgiu no século XIII no mundo árabe e era muito famoso na europa medieval. É interessante notar que a palavra aleae é traduzida por azar, mas ao mesmo tempo é raiz da palavra aleatório que tem origem etimológica no latim aleator que quer dizer relativo ao jogo de azar ou ao jogadores.

Os jogos de dados são herdeiros dos jogos realizados com astrágalos, que são ossos de animais que eram utilizados não apenas para os jogos, mas também em práticas divinatórias. David (1962) argumenta que a irregularidade desses ossos, e mesmo dos primeiros dados artesanais que surgiram mais tarde, teria dificultado a emergência da probabilidade, pois dificilmente possibilitaria a suposição de que cada lado teria uma chance igual de aparecer no lance de um dado.

Figura 1 - Dados de ossos e outros materiais utilizados como dados ${ }^{4}$

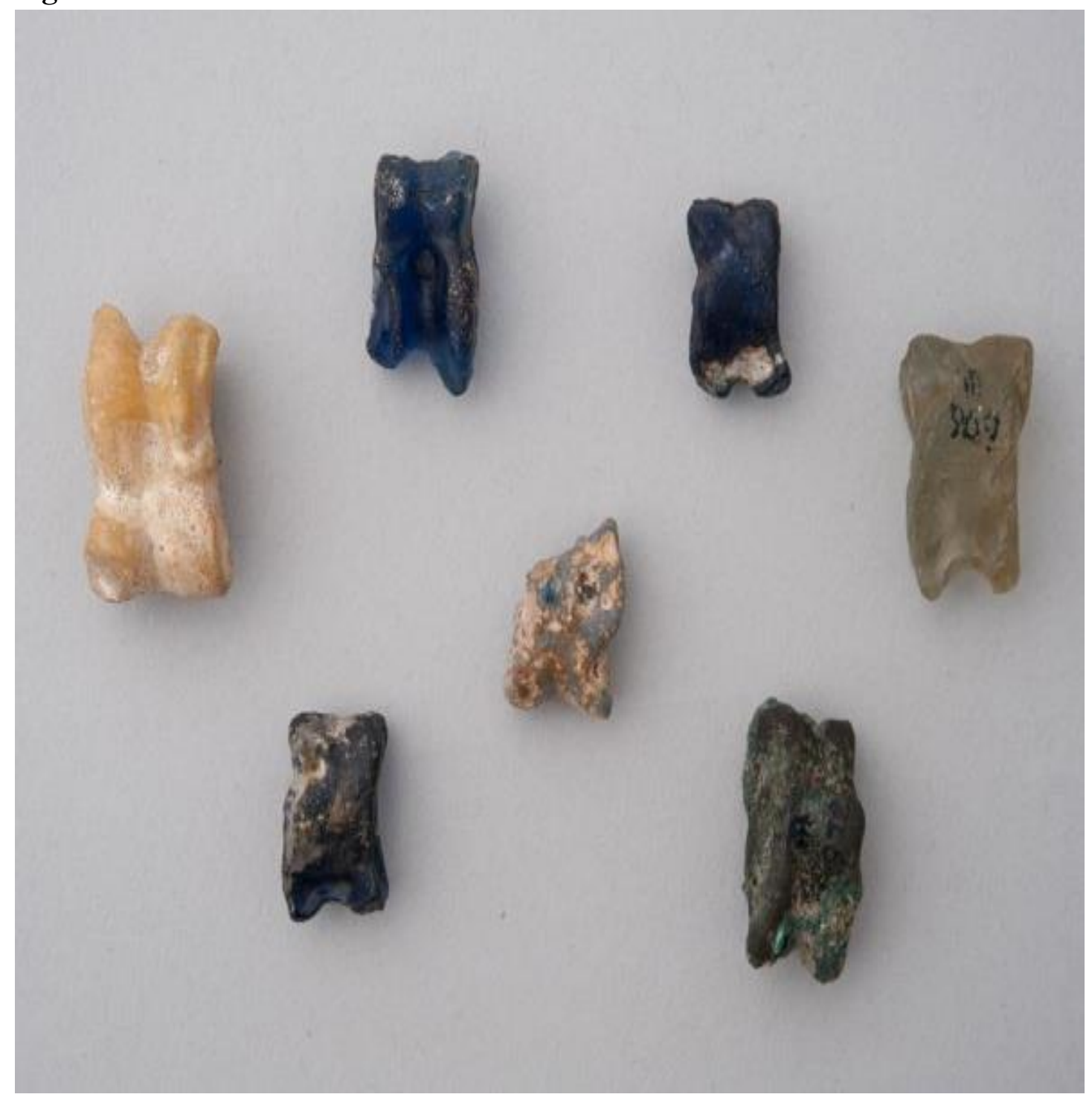

Disponível em: < $\quad$ http://archaeologicalmuseum.jhu.edu/the-collection/object-stories/archaeology-of-dailylife/childhood/knucklebones/>. Acesso: 10 maio 2020. 
Contrariando esse argumento e utilizando fontes mais recentes, Hacking (2009) mostra que dados bem balanceados já existiam desde o antigo Egito. No website do Metropolitam Museum of Art podem ser encontradas fotografias desses dados que datam do século II a.E.C., ou mais recentes entre 30 a.E.C. e 364, como nas imagens a seguir.

Figura 2 - Dados de 20 lados (antigo Egito) e 6 lados (Antiguidade Greco-romana) ${ }^{5}$

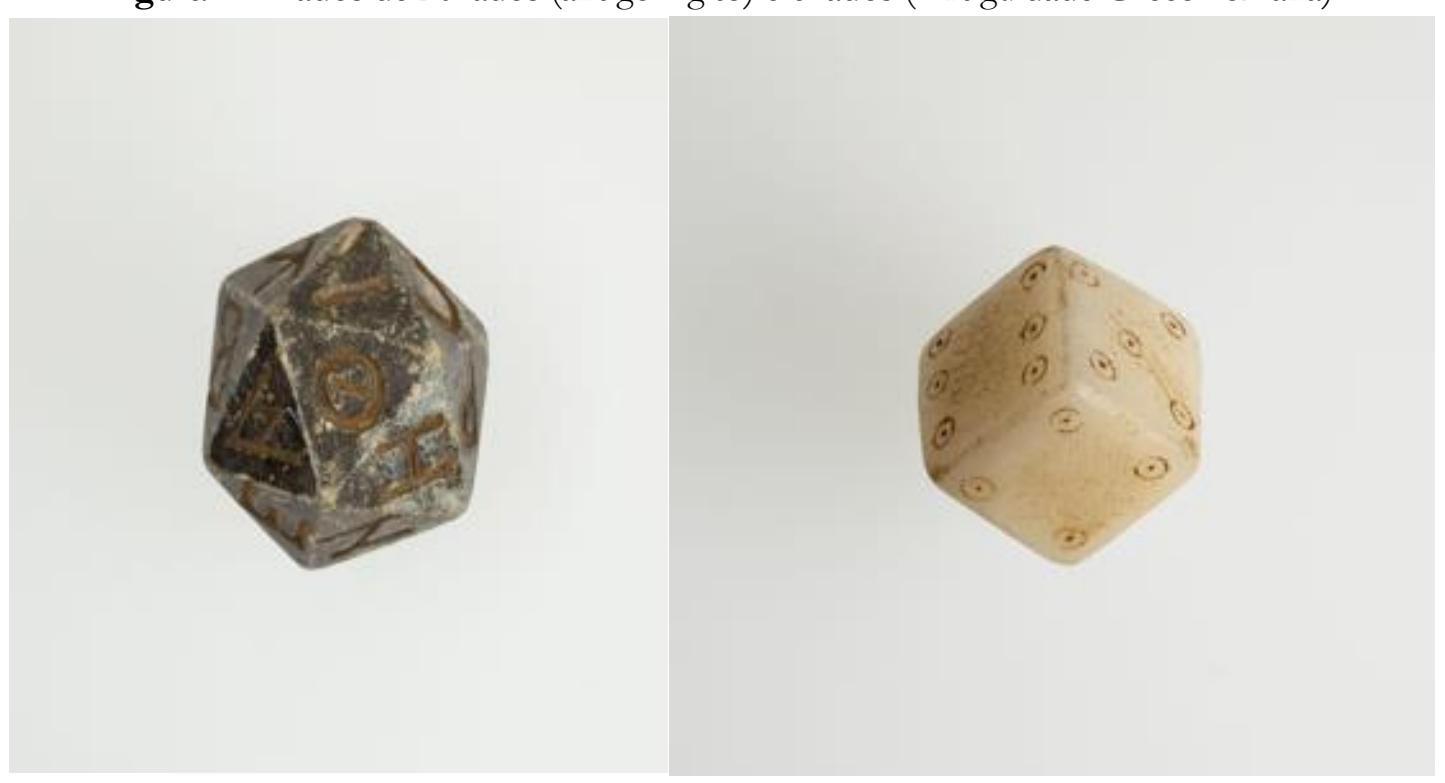

Cardano, por sua vez, estava ciente dessa diferença entre as probabilidades de diferentes dados, tendo, inclusive, dedicado o capítulo 9 de seu livro à explicação de dados feitos de ossos, os astrágalos ou talus em latim. Cardano (1953, p. 193) afirma que a proporção das apostas deve levar em consideração se o dado é ou não balanceado, mostrando clareza sobre o fato de existirem dados que são balanceados e outros que não o são.

Em seu estudo sobre a emergência da probabilidade, Hacking argumenta que, até meados do século XVII, dois aspectos fundamentais para o conceito de probabilidade estavam ausentes: o grau de crença que é garantido por evidências e a tendência que certos dispositivos aleatórios possuem de gerar frequências estáveis. Esses dois aspectos parecem estar presentes na obra de Cardano, pois, por uma lado, ele possuía a crença nas evidências mostradas pelos jogos de azar, em certos padrões, e, por outro lado os dados balanceados seriam um exemplo desses dispositivos de aleatoriedade.

$\mathrm{Na}$ próxima seção examinaremos com maior detalhes essa obra de Cardano, entretanto é importante ressaltar que o impulso de sistematização de diferentes campos do conhecimento que o levou a produzir uma vasta obra escrita em diferentes áreas não pode ser desconectado, particularmente no estudos dos jogos, das questões levantadas nesta seção. É comum no estudo da história da matemática considerar que uma visão abstrata e formalista desse campo de conhecimento teria sempre existido e que o papel do historiador da matemática seria de buscar os estágios de sucessivo aumento de abstração, desconectando as práticas matemáticas de qualquer outra prática sociocultural. Queremos

\footnotetext{
${ }^{5}$ Disponível em:

$<\underline{\text { https://www.metmuseum.org/art/collection/search/551072 }>}$

$<$ https://www.metmuseum.org/art/collection/search/551069 > . Acesso: 10 maio 2020.
} 
ressaltar que uma prática sociocultural é parte de um campo de atividade humana e que nunca pode ser vista de maneira desconexa de outras práticas. E que, além disso, práticas socioculturais ${ }^{6}$, mesmo as matemáticas, não são apenas um jogo abstrato de símbolos, mas envolvem valores, memória, intenções, desejos, poderes, instrumentos, relações humanas, trabalho, relações econômicas, dentre outros elementos. Assim, os aspectos morais e financeiros relativos aos jogos de azar não são mera futilidade que possa ser abstraída, são parte da vitalidade constitutiva das diferentes práticas humanas e particularmente das práticas matemáticas.

\section{Girolamo Cardano}

Antes de entrarmos na discussão sobre o livro de Cardano sobre jogos de azar, apresentaremos a seguir um resumo biográfico do autor. Apesar de ter vivido durante o século XVI, a obtenção de informações biográficas não é muito difícil, pois Cardano escreveu em seus últimos anos a autobiografia "De Propria Vita", a partir da qual temos acesso a várias informações sobre sua vida. Além disso, baseado nessa e em outras obras, Oystein Ore nos dá uma descrição bem detalhada dos pontos mais importantes da vida de Cardano em "Cardano, the gambling scholar", servindo como principal fonte de informação para a escrita desta seção. Vejamos, enfim, a história deste apostador intelectual.

Girolamo Cardano nasceu em 24 de setembro de 1501, filho ilegítimo de Fazio Cardano e de Chiara Micheria. Fazio, além de advogado, ensinava geometria na Universidade de Pavia e na Fundação Piatti, em Milão, e ensinou matemática a Cardano, levando-o a contemplar uma vida acadêmica. Fazio, no entanto, queria que o filho estudasse Direito e seguisse seus passos. Após várias discussões sobre o assunto, Cardano recebeu a permissão do pai para estudar medicina na Universidade de Pavia. Com o início da guerra entre Espanha e França em 1521, a universidade é fechada, forçando Cardano a completar os estudos na Universidade de Pádua.

Nesse período como estudante, Cardano iniciou a vida de apostador. Não muito depois de mudar-se para Pádua, seu pai faleceu e deixou-lhe uma pequena pensão que não lhe bastava para cobrir as despesas, o que o levou a suplantar a renda pelos jogos de azar. Tal hábito seguiu-lhe pelo resto da vida, de sorte que Cardano (1930, p. 73) fez o seguinte relato em sua autobiografia: "Eu apostei em ambos [xadrez e dados] por muitos anos, em xadrez por mais de quarenta anos, em dados por cerca de vinte e cinco; e não apenas todos os anos, mas - e eu digo isso com vergonha - todos os dias".

Após se formar em 1526, Cardano não teve muita sorte com a carreira médica, pelo menos nos primeiros anos. Devido à personalidade difícil e ao nascimento ilegítimo, ele foi inicialmente rejeitado pelo Colégio de Médicos de Milão, o que o levou a permanecer alguns anos atuando como médico em Sacco, uma pequena vila perto de Pádua, o que não lhe rendia muito dinheiro.

A pobreza de Cardano foi considerável nesses primeiros anos de carreira. Em Sacco, conheceu Lucia Bandarini, com quem se casou em 1531. Nessa época ele tentou mais uma vez ser aceito pelo Colégio de Médicos de Milão, fracassando novamente. 6 Para uma compreensão das práticas socioculturais no sentido aqui indicado ver MIGUEL, A.; VILELA, D.S. \&
MOURA, A.R.L. (2010). 
Devido à baixa renda, o casal se mudou para Gallarate, perto de Milão, em 1532. Lá, a situação de Cardano só piorou, e relembrando esse ponto de sua vida em sua autobiografia ele afirma: "[...] eu deixei de ser pobre porque nada me restava" (CARDANO, 1930, p. 15). Eventualmente, o casal se muda novamente, dessa vez para Milão, ainda em uma péssima condição financeira.

A situação de Cardano começou a melhorar após obter o cargo de professor de Matemática na Fundação Piatti em Milão, posto que já fôra do pai. Além das aulas, ele suplementava o salário atendendo alguns pacientes. Essa atuação médica tecnicamente não era legítima, uma vez que Cardano não fazia parte do Colégio de Médicos de Milão, mas ele conseguiu bons resultados e a fama como médico cresceu, trazendo-lhe vários clientes ricos e influentes.

Cardano publicou em 1536 o livro "De Malo Recentiorum Medicorum Medendi Usu Libellus", ou "Sobre as más práticas da medicina normalmente usadas", no qual listava alguns procedimentos médicos comuns considerados perigosos e incorretos por ele. Isso já poderia ter incomodado os médicos de Milão, mas Cardano decidiu também colocar uma passagem criticando o caráter fútil e as habilidades dos médicos da época. Previsivelmente, sua aplicação ao colégio no ano seguinte foi rejeitada. Por sorte, a pressão exercida por amigos e apoiadores dele finalmente convenceu o Colégio de Médicos a aceitá-lo em 1539.

Nesse mesmo ano, Cardano publicou suas duas primeiras obras de Matemática, marcando o início de uma carreira prolífica de escritor. Em sua autobiografia, ele lista nada menos que 138 livros publicados sobre temas variados, como Matemática, Física, Astronomia, Moral, Medicina, Teologia, Divinação, entre outros. Como se não bastasse, ele também lista 95 manuscritos, alguns dos quais foram publicados postumamente.

A carreira de escritor culminou em 1545 com a publicação da obra "Ars Magna", um livro de Matemática famoso por apresentar, pela primeira vez, um método para resolução de certos tipos de equação do terceiro grau. Cardano recebeu essa fórmula de Niccolò Tartaglia após muito solicitá-la, apesar de tê-la creditado no livro a Scipione del Ferro, já que ele a havia descoberto antes. A publicação da fórmula causou um atrito considerável entre Cardano e Tartaglia, já que o primeiro havia prometido ao segundo que não a revelaria. Todavia, Cardano aparenta não ter se importado muito com a indignação do colega.

No ano seguinte, em 1546, a esposa de Cardano veio a falecer aos 31 anos, deixando-o com dois filhos e uma filha. Apesar disso, a vida profissional e financeira de Cardano estava no auge. Além de lecionar medicina nas universidades de Milão e de Pavia, ele era reconhecido na época como um dos melhores médicos da Europa. Seus serviços eram requisitados por vários nobres e altos membros do clero, o que lhe rendeu muito dinheiro e até a posição de reitor do Colégio de Médicos.

Infelizmente, uma tragédia polêmica ocorre em sua família. Giambatista, o filho mais velho e preferido de Cardano, que também era médico, casou-se secretamente em 1537 com Brandonia di Seroni, uma mulher de péssima reputação, e mudou-se com ela para a casa dos pais. A família da esposa explorava Giambatista, tendo interesse apenas no dinheiro dele e do pai. Além disso, Brandonia era infiel e, durante uma das brigas do casal, afirmou que nenhum dos três filhos que haviam tido era dele. Essa situação foi a gota d'água para Giambatista, que então envenenou um bolo com arsênico e serviu para a esposa e alguns parentes dela, matando-os, o que levou ao seu encarceramento. 
Cardano tentou de todas as maneiras salvar o filho, contratando excelentes advogados, testemunhando a seu favor, escrevendo petições e pedindo ajuda para vários amigos poderosos e influentes. Os esforços de Cardano foram em vão e Giambatista foi sentenciado a pena de morte e executado em abril de 1560, antes de completar 26 anos de idade. A caminho da execução, foi torturado e teve a mão esquerda cortada.

Cardano nunca superou o fato de não ter conseguido salvar o filho. Além disso, sua reputação foi danificada por ser conhecido como o pai de um assassino, o que o levou a mudar-se de Milão para Bolonha em 1562, onde conseguiu um cargo de professor de medicina por intermédio de amigos. Lá, Cardano possuía vários colegas na universidade e o novo ambiente lhe fez bem, de modo que começou a se recuperar, logo sendo reconhecido como um dos melhores professores da universidade e recebendo uma cidadania honorária em Bolonha.

Nessa época a personalidade difícil de Cardano o levou a ter alguns problemas com colegas de trabalho, mas a grande fonte de infortúnios para ele era o filho mais novo, Aldo. Ele havia acompanhado o pai para Bolonha e se envolvia com amigos de caráter duvidoso, iniciando uma carreira criminal que o levou para a cadeia diversas vezes. Em 1569, Aldo perdeu todas as roupas, alguns bens próprios e até mesmo parte do dinheiro do pai através de apostas. Para pagar a dívida, invadiu a casa do pai e roubou uma vasta quantia de dinheiro e jóias, sendo reportado por Cardano e banido de Bolonha.

Continuando a sequência de infortúnios, Cardano foi preso por acusações de heresia em 1570. A causa imediata da prisão repentina não é clara. No entanto, Cardano havia feito algumas coisas que podem ter sido vistas como problemáticas nesse contexto, como a publicação de um livro em que elogiava o imperador romano Nero, intenso perseguidor de cristãos, e o lançamento de um horóscopo de Jesus Cristo. De qualquer maneira, a inquisição foi leniente com Cardano. Ele ficou preso apenas por poucos meses e não sofreu torturas, mas ainda assim foi punido, sendo proibido de continuar lecionando publicamente e perdendo o direito de publicar mais livros.

Cardano mudou-se então para Roma e foi muito bem recebido, sendo convidado para ingressar no Colégio de Médicos de Roma e ganhando uma pensão do Papa, que aparentemente havia perdoado-o. Apesar da proibição da Igreja, Cardano escreveu nessa época a autobiografia "De Propria Vita", publicada postumamente em 1643. Cardano faleceu em Roma em 20 de Setembro de 1576, próximo dos 75 anos. Deixou todas as propriedades para Fazio, o neto favorito dado por Giambatista, relegou uma pequena pensão para Aldo sob certas condições e cedeu alguns manuscritos e livros restantes para Rodolfo Silvestri, um grande amigo de confiança.

\section{Liber de Ludo Aleae}

Publicado apenas em 1663, o "Livro dos Jogos de Azar", apesar de conter alguns desenvolvimentos matemáticos, é um livro voltado para jogadores. Esse fato é claramente refletido na proporção dedicada a assuntos não-matemáticos, que somam mais da metade do livro. Possuindo em torno de 70 páginas na versão em inglês traduzida por Sydney Henry Gould, a obra de Cardano apresenta diversos conceitos matemáticos inovadores sobre probabilidades. Com efeito, Ore (1953) afirma que o "Liber de Ludo Aleae" é um 
documento muito importante na história da ciência, sendo o primeiro livro sobre a Teoria das Probabilidades.

Considerando a temática geral do livro, não é surpresa alguma que os conceitos de probabilidade são apresentados sempre no contexto dos jogos de azar, de modo que a maioria dos cálculos são realizados em exemplos com arremessos de dois ou três dados de seis faces. Apenas em alguns momentos Cardano lida, ainda que de maneira bem mais superficial, com jogos de cartas e com astrágalos.

Os primeiros oito capítulos do "Liber de Ludo Aleae" tratam apenas de jogos de azar e apostas, não entrando ainda em questões matemáticas. Neles, Cardano discorre sobre os tipos de jogos, determina quem deve jogar e quando, lista algumas utilidades e possíveis prejuízos provenientes dos jogos, explica alguns tipos de trapaças realizadas com dados, explicita as condições sob as quais as pessoas devem jogar, justifica por que decidiu escrever sobre o assunto e enuncia o Princípio Fundamental das Apostas.

Cardano deixa claro nesses capítulos sua opinião sobre os jogos de azar, afirmando que só se deve jogar raramente, por pouco tempo e dinheiro, contra pessoas confiáveis e de maneira justa. Nessas situações, nas quais não há preocupações de se perder muito dinheiro ou de ser trapaceado, os jogos de azar podem servir para se relaxar e divertir. Contudo, indica o autor, existem maneiras mais nobres de se passar o tempo e o ideal mesmo seria sequer jogar.

As recomendações e sugestões dos capítulos iniciais alinham-se com a justificativa dada por Cardano para a escrita do livro, que seria de apresentar as vantagens e desvantagens dos jogos de azar com objetivo de reduzir as últimas. O balanceamento dos jogos é tão importante para o autor que seu Princípio Fundamental das Apostas diz justamente que as pessoas devem sempre jogar em condições de igualdade. Segundo ele, jogar em situação de vantagem é injusto e jogar em situação de desvantagem é tolice.

Os estudos matemáticos sobre probabilidades iniciam-se apenas no capítulo 9, através de um breve tratamento sobre arremessos de um único dado. Neste capítulo, Cardano introduz o termo "circuito", utilizado por ele para se referir ao que consideramos nos dias atuais como o número total de casos equiprováveis de um experimento aleatório. No caso do lançamento de um dado, então, o circuito é 6. Analogamente, após discorrer no capítulo 10 sobre por que Aristóteles falou sobre jogos de azar, Cardano utiliza métodos de combinatória para calcular no capítulo 11 que o circuito do lançamento de dois dados é 36 e no capítulo 12 que o circuito do lançamento de três dados é 216.

Outro conceito importante apresentado no capítulo 9 é o de igualdade, que representa metade do número do circuito. No lançamento de um dado o circuito é seis e a igualdade é três, no lançamento de dois dados o circuito é 36 e a igualdade é 18, e assim por diante. Então, ao calcular probabilidades ${ }^{7}$, Cardano costuma determinar duas frações. Uma delas é a probabilidade tradicional obtida pela divisão do número $f$ de casos favoráveis pelo circuito $c$, ou seja, $p=f / c$. Já a outra, chamada de Proporção de Igualdade por Oystein Ore, é obtida pela divisão do número $f$ de casos favoráveis pela igualdade $i$, ou seja,

$$
p_{i}=f / i=2 \cdot f / c=2 p .
$$

\footnotetext{
7 Apesar de usarmos o termo "probabilidade", é importante ressaltar que Cardano não utiliza esse conceito em sua obra. Falaremos em "cálculos de probabilidade", como se diz hoje, apenas para facilitar o entendimento das ideias de Cardano, assim como Ore fez em seu livro.
} 
A princípio, a Proporção de Igualdade pode parecer estranha. Afinal, para que serviria? Ore (1953, p. 148-149) apresenta uma explicação plausível baseada no contexto dos jogos. Suponha que duas pessoas estejam participando de um jogo de azar e que cada uma aposte a mesma quantia $A$, de modo que o dinheiro acumulado dado ao vencedor, chamado de pote, será $2 A$. Se um dos jogadores tem probabilidade $p$ de vencer o jogo, a expectativa dele será de ganhar a quantia $E=p \cdot 2 A$. Entretanto, seria natural considerar as perdas e ganhos do jogador não em relação ao pote $2 \mathrm{~A}$, mas à quantia $\mathrm{A}$ que apostou. Nesse sentido, a expectativa de ganho do jogador pode ser reescrita como

$$
E=p \cdot 2 A=2 p \cdot A=p_{i} \cdot A
$$

fazendo da Proporção de Igualdade um fator natural para medir perdas e ganhos.

Passemos agora para um conceito verdadeiramente problemático de Cardano, intitulado por Ore de reasoning on the mean, ou seja, raciocínio sobre a média. O raciocínio sobre a média é um método simples desenvolvido por Cardano para calcular a probabilidade de que um evento aconteça em um certo número de tentativas. Para explicálo, pensemos em um exemplo. Como um dado comum tem 6 lados e cada um deles tem uma chance de 1/6 de aparecer em um arremesso, "esperamos" que cada lado apareça uma vez em seis lançamentos. Assim, se jogarmos um dado três vezes seguidas, a chance de que um certo lado apareça é de $3 \cdot 1 / 6=1 / 2$. Afinal, se um lado "deve" aparecer em 6 jogadas, ele "deve" aparecer metade das vezes em metade das jogadas.

Utilizando uma notação algébrica, podemos dizer que o raciocínio sobre a média funciona da seguinte maneira: se $f$ é o número de casos favoráveis e $c$ é o número do circuito, uma única tentativa nos dará uma chance de $p=f / c$ de termos sucesso. Duas tentativas nos dará uma chance de $2 \cdot \mathrm{f} / \mathrm{c}$, três tentativas uma chance de $3 \cdot \mathrm{f} / \mathrm{c}$, e assim sucessivamente. O problema é que esse raciocínio está incorreto. De fato, o raciocínio sobre a média diz que se jogarmos um dado comum seis vezes a chance de que um certo lado apareça é de $6 \cdot 1 / 6=1=100 \%$, o que sabemos ser absurdo.

O uso do raciocínio sobre a média é responsável pela maioria dos erros cometidos por Cardano no livro. Por exemplo, ao lidar com a probabilidade de que um certo número apareça pelo menos uma vez em três lançamentos sucessivos de um dado no capítulo 12, Cardano inicialmente utiliza o raciocínio sobre a média. Segundo sua lógica, como o 6 tem uma chance de $1 / 6$ de aparecer em uma única tentativa, sua chance de aparecer em três tentativas será de $3 \cdot 1 / 6=1 / 2=108 / 216$. No capítulo 14 , no entanto, Cardano percebe que um dado número qualquer aparece na verdade em 91 dos 216 casos possíveis no lançamento de três dados, de maneira que a probabilidade correta é de 91/216.

Podemos perceber que quando Cardano calcula as probabilidades dos lançamentos de dados por métodos de combinatória, contando o número de casos favoráveis e o de casos totais e dividindo o primeiro pelo segundo, ele chega facilmente nos resultados corretos. O problema ocorre quando, por ser um procedimento bem mais fácil e rápido de aplicar, ele decide utilizar o raciocínio sobre a média, chegando em resultados no máximo aproximadamente certos.

No capítulo 13, Cardano volta-se para as probabilidades de vários lançamentos de dois ou três dados, apresentando resultados para os jogos Sors e Fritillus. Ore (1953) indica 
que o objetivo do primeiro jogo é simplesmente tirar um ponto total específico com os dados, enquanto o segundo provavelmente era uma espécie de Gamão jogado com três dados em vez de dois. Cardano enumera neste capítulo quais são os resultados possíveis para o jogo Sors com dois dados, bem como os resultados possíveis para Sors e Fritillus com três dados.

Em relação aos cálculos de Cardano nesse capítulo, como o jogo Sors é bem simples e sabemos suas regras é fácil confirmar que os resultados obtidos por ele estão corretos. O mesmo não pode ser dito sobre o Fritillus, cujas regras desconhecemos. Ore (1953), por exemplo, tentou fazer o trabalho inverso, ou seja, supôs que os cálculos estivessem corretos e tentou reformular as regras do jogo a partir deles.

Passando para o Capítulo 14, Cardano lida com combinações de pontos com dados. Começando com lançamentos de dois dados, o autor determina que existem 11 maneiras de se tirar um certo número, digamos o ás, em pelo menos um dos dois dados. Por sua vez, existem 20 maneiras de se tirar um ás ou um dois e 27 maneiras de se tirar um ás, um dois ou três. Cardano prossegue assim até as 36 maneiras de se tirar qualquer um dos seis lados. De maneira análoga, ele calcula que existem 91 maneiras de se tirar um ás no lançamento de três dados, 152 maneiras de se tirar um ás ou um dois e assim por diante.

Como o tema central do livro são os jogos de azar, devemos notar que a partir do capítulo 14 Cardano começa a expor os resultados de probabilidade em um formato mais útil para apostadores. Em vez de dizer, por exemplo, que a probabilidade de se tirar um ás, um dois ou um três no lançamento de dois dados é de $27 / 36$, ele diz que as chances são de 27 para 9 ou, simplificando os valores, de 3 para 1, o que significa que existem três possibilidades de sucesso para cada possibilidade de fracasso. Essa formatação é interessante por indicar diretamente aos jogadores quanto devem apostar para que joguem em condições de igualdade.

Com efeito, Cardano apresenta um exemplo que deixa isso claro. Suponhamos que um jogador $A$ aposte três ducados que tirará um ás, um dois ou um três no lançamento de dois dados e que um jogador B aposte um ducado que A fracassará. Pelos cálculos de probabilidade apresentados acima, se A e B jogarem quatro vezes esperamos que A ganhe três vezes, recebendo três ducados de $\mathrm{B}$, e que $\mathrm{B}$ ganhe uma vez, recebendo três ducados de A. Logo, espera-se que ninguém ganhe ou perca dinheiro com o jogo, o que indica que ele é justo.

Para encerrar as análises de Cardano sobre lançamentos de dados, falemos sobre um dos feitos mais importantes da Teoria das Probabilidades do autor, que foi o desenvolvimento do método para calcular probabilidades de eventos repetidos. No final do capítulo 14, Cardano tenta calcular a chance de uma pessoa tirar um ás no lançamento de dois dados duas vezes seguidas. Assim, ele afirma que uma vez que as chances de se tirar um ás no lançamento de dois dados são de 91 para 125, então as chances de fazê-lo duas vezes seguidas devem ser de $91^{2}$ para $125^{2}$, ou seja, de 8.281 para 15.625. Analogamente, as chances de se tirar um ás no lançamento de dois dados três vezes seguidas seria de $91^{3}$ para $125^{3}$, e assim por diante.

Entretanto, Cardano inicia o capítulo 15 de seu livro afirmando que o raciocínio dele deve estar incorreto. Afinal, indica ele, supondo que estivesse correto, como as chances de um jogador tirar um número par no lançamento de um dado são de 1 para 1 , as chances de se tirar dois números pares seguidos serão de $1^{2}$ para $1^{2}$ e as de se tirar três 
números pares seguidos de $1^{3}$ para $1^{3}$. Prosseguindo dessa maneira, podemos perceber que a probabilidade de se tirar qualquer quantidade seguida de números pares será sempre de $50 \%$, o que é claramente um absurdo.

Tentando resolver esse problema, Cardano decidiu dividir a questão das probabilidades de eventos repetidos em dois casos. Inicialmente, ele volta a atenção para os eventos cuja probabilidade individual é de $1 / 2$, como por exemplo tirar um número par no lançamento de um dado. A regra determinada por Cardano é a seguinte: multiplique o número de lançamentos seguidos por si mesmo e subtraia 1 do resultado. A chance de sucesso será de 1 para esse resultado. Assim, se jogarmos um dado duas vezes, multiplicamos 2 por 2, obtendo 4, e subtraímos 1 de 4, o que dá 3. Logo, a chance de tirarmos um número par duas vezes será de 1 para 3. Do mesmo modo, jogando um dado três vezes nós multiplicamos 3 por 3, obtendo 9, e subtraímos 1 de 9, o que dá 8. Logo, a chance de tirarmos um número par três vezes será de 1 para 8 .

No entanto, esse método está incorreto. Utilizando a notação algébrica, ele nos diz que a chance de um evento de probabilidade $1 / 2$ ocorrer $n$ vezes seguidas é de 1 para $n^{2}$ 1. Entretanto, a chance verdadeira é de 1 para $2^{\mathrm{n}}-1$, o que nos dá uma probabilidade de $1 / 2^{\mathrm{n}}$. De qualquer modo, é um tanto estranho que Cardano tenha decidido formular um método exclusivo para os casos de probabilidade $1 / 2$, visto que, como já sabemos atualmente, não há necessidade para tal.

Nos casos em que a probabilidade individual do evento é diferente de 1/2, Cardano utiliza um método que, além de correto, funcionaria também nos casos de probabilidade $1 / 2$. Suponha que lançamos dois dados e queremos tirar um ás, um dois ou um três em qualquer um deles, cujas chances são de 3 para 1. Qual é a probabilidade de conseguirmos tal feito duas vezes seguidas? Para facilitar os cálculos, Cardano considera um dado de 4 lados com um número par em um lado e um número ímpar nos três lados restantes. Assim, a probabilidade de tirarmos um número ímpar duas vezes seguidas com esse dado é igual à probabilidade que procuramos. $\mathrm{O}$ autor observa então que ao lançarmos esse dado duas vezes teremos $4 \cdot 4=16$ possíveis resultados, dos quais 9 serão formados por dois números ímpares e 7 por um ou dois números pares. Logo, as chances procuradas são de 9 para 7.

A partir desse e outros exemplos similares, Cardano (1953, p. 204) generaliza o método, afirmando que "[...] em todos esses casos o número inteiro é multiplicado por si mesmo e similarmente o número de faces similares por si mesmo, e esse último número é comparado com o resto". Usando a notação algébrica atual, sendo $c$ o número total de casos e $f$ o número de casos favoráveis, as chances de se obter sucesso duas vezes seguidas são de $f^{2}$ para $c^{2}-f^{2}$, o que dá a probabilidade $(f / c)^{2}$. Cardano (1953) também indica que o método funciona de forma análoga para três ou mais jogadas, de modo que as chances de se obter sucesso três vezes seguidas são de $f^{3}$ para $c^{3}-f^{3}$, o que dá a probabilidade $(f / c)^{3}$, e assim por diante.

A parte principal da Teoria de Probabilidades de Cardano acaba aqui, no capítulo 15. O capítulo 16 do "Liber de Ludo Aleae" lida com algumas probabilidades envolvendo o jogo de cartas Primero. Contudo, para entender bem esse capítulo seria necessário explicar as regras do jogo e as possíveis combinações de cartas, o que demandaria tempo. Como os cálculos de probabilidade em si não trazem nada de novo em comparação com as análises feitas sobre dados, deixaremos essa parte da obra de lado. 
A maioria dos capítulos restantes do livro, do 17 ao 30, tratam de questões gerais de jogos de azar. Neles Cardano dá explicações sobre o jogo Primero, fala sobre o papel da sorte no jogo, refuta o mito de que lançar dados sem força dá azar, formula divisões entre os tipos de jogos, explica um pouco do jogo Trappola, diferencia os jogos de dados e de cartas, lista alguns jogos de cartas, afirma que compreender jogos de azar não te torna um bom jogador, discorre sobre a importância do planejamento no gamão, informa que caráter deve ter um jogador e, por fim, fala sobre alguns jogos dos povos antigos.

O capítulo 31 volta-se mais uma vez para os cálculos de probabilidade, dessa vez em relação aos astrágalos. $O$ autor calcula quantas combinações são possíveis no lançamento de 4 astrágalos, chegando à resposta correta de 256 e calculando, a partir desse resultado, as probabilidades de alguns lançamentos específicos. Não temos aqui qualquer novidade em termos matemáticos, já que Cardano utiliza os mesmos métodos que havia aplicado nos casos de dados de seis lados.

A obra de Cardano acaba no capítulo 32. Aqui ele apresenta brevemente o conceito de número médio, obtido pela divisão da soma dos resultados possíveis pelo número de casos. Por exemplo, como a soma dos resultados do lançamento de um dado de seis lados é $1+2+3+4+5+6=21$ e temos seis casos, o número médio desse lançamento é de $21 / 6=7 / 2$. O autor encerra o livro, então, com a afirmação de que é lícito utilizar os jogos de azar para relaxar a mente ou passar o tempo.

O "Liber de Ludo Aleae" foi uma obra inovadora, trazendo conceitos e métodos novos para resolver problemas de probabilidade. Cardano cometeu certos equívocos, é claro, mas devemos levar em consideração o caráter inédito de seu trabalho. Mesmo com todos os erros, Cardano acertou em muitos pontos e, ao nosso ver, merece o crédito de ser um dos pioneiros na área de estudo das probabilidades.

\section{Probabilidades dentro e fora da escola}

Ao longo do capítulo argumentamos sobre as conexões entre o campo de atividade dos jogos e o surgimento da Teoria de Probabilidades. Os jogos de dados em particular tiveram um papel importante na primeira tentativa de sistematização das probabilidades feita por Cardano. Procuramos ressaltar que as práticas lúdicas tem importância histórica para diferentes culturas (Huizinga e Caillois), sendo inclusive constitutivas de diferentes formas de vida, e não apenas mera distração. Além disso, o fato das apostas terem sido para Cardano uma questão de subsistência - ou mesmo um vício - em certos momentos, possibilitou a esse pensador dar um tratamento a aleatoriedade que até o momento não havia sido dado.

Se dermos um salto para o contexto brasileiro atual - aproximadamente 400 anos depois - e olharmos para como alguns livros didáticos tratam o assunto das probabilidades, podemos encontrar inúmeros semelhanças de família entre esses dois contextos históricos. Procuraremos apontar nesta seção como as práticas escolares propostas por livros didáticos apresentam o trabalho com probabilidades usando contextos de jogos de azar, mas procurando depurá-los de seu caráter moralmente repreensível e criando uma desconexão dessas práticas com o mundo fora da escola, as formas de vida efetivas. 
Vamos analisar livros de duas coleções que estão adequadas à proposta da BNCC para os Anos Finais do Ensino Fundamental: “A Conquista da Matemática” " "Projeto Teláris”. Apresentaremos como os autores introduzem e desenvolvem os conceitos da teoria das probabilidades, por meio de situações-problema, exemplos e exercícios. Em seguida, problematizamos essa forma de apresentação em relação ao contexto de surgimento das probabilidades na obra de Cardano.

Na coleção “A conquista da Matemática”, de Giovanni Júnior e Castrucci (2018a, p. 192), o cálculo de probabilidades é introduzido de maneira intuitiva pela primeira vez no livro do sexto ano como uma aplicação de números decimais e porcentagens à seguinte situação-problema: "Você tem um dado de seis faces numeradas de 1 a 6 e o lança uma vez. Qual a probabilidade de o dado cair com a face 1, 3 ou 5 (os números ímpares) virada para cima?". O lançamento de um dado aparece desconectado de qualquer prática sociocultural, é uma situação hipotética, criada para a escola. Em seguida, algumas atividades em grupo são propostas para análise de probabilidades do lançamento de dados e do experimento de tirar fichas de dentro de uma urna. Podemos nos questionar em que prática social é necessário conhecer a probabilidade de tirar elementos de uma urna. A resposta nos levaria ao campo dos jogos de azar, pois o bingo talvez seja uma das únicas práticas em que saber as chances de retirada de um número de uma urna faça sentido.

No livro do sétimo ano da mesma coleção, o exemplo da urna inicia o trabalho com as probabilidades: "A professora Leila colocou em uma urna 15 bolinhas azuis, 25 bolinhas vermelhas e 10 bolinhas amarelas, todas de mesmo tamanho. Ela pediu que Artur retirasse, sem olhar, uma bolinha da urna, mas antes perguntou para a sala qual cor de bolinha ele teria a maior chance de retirar da urna: azul, vermelha ou amarela" (GIOVANNI JÚNIOR; CASTRUCCI, 2018b, p. 243). A partir dela são calculadas as probabilidades de se retirar cada uma das cores, e a fórmula da probabilidade é apresentada. Alguns exercícios similares são propostos e, em seguida, são apresentadas as definições de experimento aleatório, espaço amostral e evento por meio do exemplo de lançamento de uma moeda. Dentre os exercícios do livro, um deles refere-se a lances de um dado honesto: "Chamamos de dado honesto aquele cuja probabilidade de ocorrência de qualquer face é a mesma” (GIOVANNI JÚNIOR; CASTRUCCI, 2018b, p. 244). Aqui também não há comentários sobre de onde teria surgido a necessidade de um dado "honesto".

No livro do oitavo ano, Giovanni Júnior e Castrucci (2018c) apresentam novamente os conceitos de experimento aleatório, espaço amostral e a fórmula de cálculo de probabilidades por meio do exemplo do lance de dados honestos, mas agora introduzindo a notação de conjuntos. Nos exercícios da seção, outros jogos aparecem, como as cartas e o jogo de tirar uma bola de uma urna que, apesar de remeter ao bingo, apaga a referência a essa prática e cria uma situação depurada dos elementos indesejados do mundo fora da escola.

Na coleção "Projeto Teláris Matemática”, de Luiz Roberto Dante e Fernando Viana, as probabilidades aparecem no sexto ano através de um exemplo com lançamento de uma moeda. Os autores explicam que existem dois resultados possíveis para a face voltada para cima: sair cara ou sair coroa, e que se a moeda for "honesta" a chance de sair cara é igual à chance de sair coroa. Introduzem, então, os conceitos de probabilidade e de resultados equiprováveis. Em seguida definem o espaço amostral, já utilizando a notação de conjuntos, e explicam que se os resultados possíveis de um espaço amostral são 
equiprováveis, calculamos a probabilidade de um resultado ocorrer dividindo o número de resultados favoráveis pelo número de resultados possíveis (DANTE; VIANA, 2019a, p. 322).

No livro do sétimo ano dessa mesma coleção, Dante e Viana (2019b) definem experimentos aleatórios e retomam a definição de espaço amostral, aproveitando para introduzir o conceito de eventos como subconjuntos do espaço amostral. Em seguida, após definirem eventos certos e eventos impossíveis, explicam como calcular a probabilidade de um evento de um espaço amostral equiprovável. É também interessante ressaltar que em um pequeno texto sobre a história dos jogos, Dante e Viana (2019b, p. 295) citam Cardano, afirmando que "O primeiro texto relacionado a jogos de azar e à Matemática foi escrito pelo médico, matemático, filósofo e jogador Gerolamo Cardano (1501-1576), em 1550, e publicado apenas em 1663: "O livro sobre os jogos de azar".

Nesses livros a questão dos jogos aparece nos exemplos e nos exercícios, ainda que de maneira diluída, removendo quaisquer menções de apostas, assim como feito na coleção "A Conquista da Matemática". No livro do $6^{\circ}$ ano o exemplo utilizado para introduzir o assunto é o lançamento de uma moeda, e os exercícios envolvem cálculos de probabilidade em situações como a retirada de bolinhas coloridas de um saco ou de uma urna, o giro de uma roleta com 4 cores e o lançamento de um dado. Analogamente, no livro do $7^{\circ}$ ano os principais exemplos envolvem o lançamento de dados, incluindo ainda o lançamento de moedas e retirada de cartas de um baralho. Os exercícios, por sua vez, também envolvem roletas, urnas, sorteios, dados e cartas.

Apesar do uso frequente de práticas de jogos de azar para introduzir o trabalho com probabilidades, a problematização da história, dos valores, das questões éticas e morais envolvidas nos jogos de azar, ou seja, a problematização de como essas práticas são efetivamente realizadas em diferentes formas de vida, são completamente ignoradas pelas práticas escolares. Daí parece decorrer a dificuldade que os estudantes têm em ligar a matemática que aprendem na escola com qualquer coisa da vida real.

O diálogo com a história pode ser um dos elementos a auxiliar que o fora da escola possa ser problematizado dentro da escola. Por exemplo, a questão da necessidade de um dado ser honesto é abordada pelo próprio Cardano, que inclusive recorre aos ancestrais dos dados, o talus ou astrágalo:

O talus possui quatro lados e, assim, quatro pontos. Mas um dado possui seis; em seis lances cada ponto deveria aparecer uma vez; mas como alguns se repetirão, outro não irão aparecer. (CARDANO, 1953, p. 192)

As apostas portanto devem estar em acordo com essa igualdade se o dado é honesto, caso contrário devem ser feitas de maneira proporcional à diferença da verdadeira igualdade de chances. (CARDANO, 1953, p. 193)

Além de apresentar claramente a questão do valor das apostas em relação às chances de vitória, Cardano nos remete a própria história da materialidade dos dados como apresentamos na segunda seção deste capítulo. Uma problematização de tal prática no campo escolar deveria levar em conta esses elementos de maneira a aproximar a escola do 
mundo fora dela. Claro que envolvem questões morais, mas a escola parece ignorar que elas existem, como se as crianças e jovens não as confrontassem.

Ambas as coleções didáticas, ao introduzirem os conceitos da teoria das probabilidades, utilizam-se fartamente de práticas que possuem relações com os jogos de azar. O lançamento de um dado de seis lados, apesar de também ser útil em muitos jogos de tabuleiro, tem sua origem ligada aos jogos de azar e às práticas divinatórias. Outra prática recorrente é a retirada de bolas de uma urna que está diretamente relacionada com bingo, jogo de azar que é proibido, embora muito presente em eventos escolares para a arrecadação de fundos. Por fim, o jogo de roleta também aparece de maneira desconfigurada no livro de Dante e Viana (2019a) em um exercício envolvendo uma roleta dividida em quatro seções com cores distintas. Também, os jogos de cartas são utilizados para o trabalho com as probabilidades desconsiderando o contexto de jogos de azar ou das práticas lúdicas frequentes entre amigos e famílias.

Esses são exemplos de como a escola organiza seus conteúdos de maneira a desconsiderar a vida fora da escola. A história da matemática, como no exemplo de Cardano que trazemos neste capítulo, pode auxiliar na recuperação dessas questões vitais que são partes importantes das formas vida humanas na constituição de conceitos em diferentes áreas de conhecimento. Em vez de apresentarmos práticas (de lançamento de dados ou moedas, de tirar bolas de urnas, de tirar cartas de baralho) desconectadas dos campos de atividade humana, de suas formas de vida, a história pode trazer a vitalidade que fica ocultada pela maneira desconexa com que as práticas escolares são apresentadas aos estudantes.

\section{Referências}

BRASIL. Base Nacional Comum Curricular (BNCC). Educação é a Base. Brasília, MEC/CONSED/UNDIME, 2017.

CAILLOIS, R. Os Jogos e os Homens: a máscara e a vertigem. Lisboa: Cotovia, 1990.

CARDANO, G. The book on games of chance. In: ORE, O. Cardano: The Gambling Scholar. Princeton: Princeton University Press, 1953. p. 182-241.

The book of my life. Nova Iorque: E. P. Dutton, 1930.

DANTE, L. R.; VIANA, F. Teláris matemática: 6º ano. 3. ed. São Paulo: Ática, 2019a. Teláris matemática: $7^{\circ}$ ano. 3. ed. São Paulo: Ática, 2019b.

DARDOT, P.; LAVAL, C. A Nova Razão do Mundo: ensaio sobre o neoliberalismo. São Paulo: Boitempo, 2016.

DAVID, F. Games, gods and gambling: The origins and history of probability and statistical ideas from the earliest times to the Newtonian era. Griffin, 1962. 
GIOVANNI JÚNIOR, J. R.; CASTRUCCI, B. A conquista da matemática: 6o ano ensino fundamental: anos finais. 4. ed. São Paulo: FTD, 2018a.

A conquista da matemática: 70 ano - ensino

fundamental: anos finais. 4. ed. São Paulo: FTD, 2018b.

A conquista da matemática: 80 ano - ensino

fundamental: anos finais. 4. ed. São Paulo: FTD, 2018c.

HACKING, I. The Emergence of Probability: A philosophical study of early ideas about probability, induction and statistical inference. 2. ed. Nova Iorque: Cambridge University Press, 2006.

HUIZINGA, J. Homo ludens: O jogo como elemento da cultura. São Paulo:

Perspectiva, 2012.

MIGUEL, A.; VILELA, D. S.; MOURA, A. R. L. Desconstruindo a matemática escolar sob uma perspectiva pósmetafísica de educação. Zetetikê, Campinas, v. 18, número temático, p. 129-206, 2010.

MLODINOW, L. O andar do bêbado. Rio de Janeiro: Zahar, 2009.

ORE, O. Cardano: The Gambling Scholar. Princeton: Princeton University Press, 1953. 